\title{
Plate shape and colour interact to influence taste and quality judgments
}

\author{
Peter C Stewart ${ }^{*}$ and Erica Goss
}

\begin{abstract}
Background: Research has demonstrated that factors external to the food source can influence consumers' perceptions of food. Contextual factors including cutlery or tableware (for example, size and composition), the atmosphere (for example, noise levels and odours), and packaging (for example, shape and colour) have all been shown to influence the perceptual experience. Plateware has also been shown to influence taste perception since ratings of a dessert (strawberry mousse) were modified by plate colour but not by plate shape. In the current study, which used a $2 \times 2$ between-subjects design, the effect of plate colour (black versus white) and plate shape (round versus square) on taste perception is re-examined. Through sweetness, intensity, quality, and liking ratings of cheesecake, the current study extends the previous investigation to include an examination of the plate colour by plate shape interaction while using plates with more angular corners.

Results: Judgments made on simple elemental properties (sweetness and flavour intensity) and higher level compound property judgments (food quality or food liking) were shown to be differentially influenced by the interaction of plate colour and plate shape. Both elemental and compound property judgments were heightened by white round plates while compound judgments were also increased when food was presented on black square plates.

Conclusions: The results suggest that plate colour and shape influence taste perception but not in a straightforward manner and instead the influence depends on the interaction of the two variables. Depending on which attribute of the perceptual experience is more important, knowledge of this interaction could be used advantageously by the culinary community.
\end{abstract}

Keywords: Taste perception, Plate, Shape, Colour, Sweetness, Flavour intensity, Food quality, Cross-modal, Preferences

\section{Background}

Most people would correctly say that taste is determined by more than just taste receptors on the tongue but they may be surprised by the extent to which this is true. Along with the gustatory response, it is commonly recognized that what a food smells like (olfactory cues), how it looks (visual cues), and how it feels in your mouth or hands (somatosensory cues) all influence the resulting perception of taste. However, it is not only the attributes of the food that influence taste perception, and instead, environmen$\mathrm{tal} /$ contextual factors also greatly impact the resultant perception of taste. The current study examined two factors external to the food source, plate shape and plate colour,

\footnotetext{
* Correspondence: pstewart@grenfell.mun.ca

Psychology Program, Grenfell Campus, Memorial University of Newfoundland, University Avenue, Corner Brook, NL A2H 6P9, Canada
}

for their effect on perceptual judgments of sweetness, intensity, quality, and liking.

Research has shown that the manipulation of a variety of food-specific cue types will influence various aspects of taste perception. Olfactory cues have been shown to manipulate our perception of taste with a number of studies having shown an enhancement of sweetness ratings in response to pairing a food with odours usually associated with sweetness [1-3]. Additionally, in two experiments, Stevenson, Prescott, and Boakes [4] paired 20 different odours with sucrose taste solutions (E1) and citric acid taste solutions (E2). They found that odours with a strong learned association with sweetness (for example, caramel) enhanced sweetness ratings and suppressed sour ratings, thereby showing the importance of learning and memory in taste perception. In a more recent investigation, Djordjevic, Zatorre, and Jones-Gotman [5] also found an 
odour-induced change in taste perception (OICTP) when they paired olfactory and gustatory stimuli. Specifically, the smell of strawberries led to a sweetness enhancement and a soy sauce odour increased ratings of saltiness.

The texture of food has also been shown to modify the perceptual experience [6-8]. Cook, Hollowood, Linforth, and Taylor [9] found that ratings of sweetness were significantly lessened in thicker solutions. Additionally, Walker and Prescott [10] showed that apple juice flavour was rated less sweet in a more viscous solution. Further, texture has been shown to directly and indirectly, via its influence on chewing parameters, influence flavour release (see Salles et al. [11] for a review).

Shape is closely related to texture and certain attributes of food seem to reliably share a synaesthetic relationship with shapes. Synaesthesia is a phenomenon whereby the stimulation of one sensory modality simultaneously produces an accompanying stimulation in a second sensory modality. Cytowic [12] discusses a synaesthete who tasted shapes. For this individual, an amateur chef who cooked according to the shape of the food rather than following any recipes, shapes had tastes and certain shapes tasted better than others. Although synaesthesia typically refers to a non-standard 'crossing' of the senses, it seems that when it comes to food we may all be synaesthetes to some extent. Research in non-synaesthetes has shown that most individuals have shape associations with certain food qualities. For example, wines are often described as having a rounded or pointed taste [13]. Particularly relevant to the current study, it has also been shown that sweetness is often associated with round shapes while bitterness and saltiness are associated with angular shapes $[14,15]$. Whether this flavour-shape association extends to environmental factors external to the food source is one focus of the current study.

Perhaps the most profound manipulation of the perceptual experience is driven by visual input. Specifically, it has been repeatedly shown that modifying the colour of a standard food influences the taste perception of that food [16-19]. Garber, Hyatt, and Starr [20] examined the effect of incongruent colours (and labelling) on taste perception of noncarbonated fruit drinks. By manipulating the colour of an orange-flavoured drink (orange versus purple versus clear) the researchers showed that participants were significantly less likely to correctly identify the flavour if the beverage was coloured purple or clear. They also reported an interaction between stimulus colour and package labelling for ratings of naturalness/expensiveness. This suggested that external factors, factors not directly related to the food itself, can influence perception of higher level cognitive judgments [20]. Whether this colour influence generalises to environmental stimuli, such as the colour of plate the food is presented on, is examined in the current investigation.
Recently, perception research has supported that the environment or context surrounding the food has been shown to be a significant modulator of taste perception [21]. Specific contextual variables include, but are not limited to, background music [22]; the size, weight, and composition of cutlery [23]; a product's packaging [24]; colour lighting [25]; and menu item naming [26].

An additional environmental variable that has come under recent scrutiny was plateware [27]. In two separate experiments, the researchers examined the potential influence of plate colour (E1: black versus white) and plate shape (E2: round versus square versus triangular) on ratings of sweetness, intensity, quality, and liking. All attribute ratings, except quality ratings, were shown to be significantly increased when the strawberry mousse was presented on white plates when compared to black plates. However, contrary to expectations, plate shape had no significant influence on attribute ratings. In addition to concluding that plate colour is a significant contributor to taste perception, the authors suggested that the jury was still out on plate shape since their plates may have been somewhat less angular than desired due to the plate corners being rounded. Further, Piqueras-Fiszman et al. [27] did not examine the interaction between plate colour and plate shape.

Like the Piqueras-Fiszman et al. studies, the majority of research into taste perception has taken a single attribute approach and only manipulated one environmental variable per experiment. It has been suggested that an important goal of future research should be to examine the simultaneous interaction of two or more environmental variables [21]. Continuing from the Piqueras-Fiszman et al. work, the current study replicated and extended the aforementioned findings using plates with more angular corners and by employing a factorial design. Results revealed significant interactions between plate shape and plate colour across each of the rated attributes.

\section{Results}

Aware that we had relatively small sample sizes in each experimental group $(n=12)$, we felt it important to first examine the experimental groups' composition for any pre-existing differences that may have confounded the results. We felt that these preliminary analyses were necessary since, as stated and referenced multiple times in the paper's introduction, many variables can exert a large influence on perception. All analyses were independent measures analyses and were tested against an alpha level of .05. Sample sizes, means, and standard deviations displayed as a function of gender and plate type can be seen in Table 1. Group composition did not significantly differ as a function of age or gender ${ }^{\mathrm{a}}$ suggesting our groups were well matched in terms of age and gender. 
Table 1 Group characteristics and attribute descriptive statistics as a function of plate colour, plate shape, and participant gender $(n=48)$

\begin{tabular}{|c|c|c|c|c|}
\hline Variable & White round & White square & Black round & Black square \\
\hline \multicolumn{5}{|l|}{ Male } \\
\hline$n(N=27)$ & 6 & 8 & 9 & 4 \\
\hline Age (years) & $20.50(2.20)$ & $20.50(2.20)$ & $21.44(5.48)$ & $20.50(3.70)$ \\
\hline Sweetness (\%) & $77.50(10.60)$ & $55.04(13.24)$ & $49.46(13.60)$ & $63.31(10.35)$ \\
\hline Intensity (\%) & $77.87(14.38)$ & $38.37(20.05)$ & $47.49(21.12)$ & $50.81(20.60)$ \\
\hline Quality (\%) & $82.62(21.78)$ & $70.30(20.50)$ & $66.61(18.98)$ & $70.43(18.95)$ \\
\hline Liking of sample (\%) & $85.48(24.38)$ & $70.09(24.62)$ & $71.92(12.42)$ & $87.50(8.34)$ \\
\hline Hunger (\%) & $44.27(16.71)$ & $53.43(22.24)$ & $45.88(19.08)$ & $65.32(26.75)$ \\
\hline Liking in general (\%) & $85.93(11.60)$ & $59.81(19.20)$ & $71.15(21.31)$ & 77.96 (19.98) \\
\hline \multicolumn{5}{|l|}{ Female } \\
\hline$n(N=21)$ & 6 & 4 & 3 & 8 \\
\hline Age (years) & $23.67(6.77)$ & $20.75(0.96)$ & $19.67(2.52)$ & $27.63(13.00)$ \\
\hline Sweetness (\%) & $68.37(18.27)$ & $59.41(7.04)$ & $55.38(16.83)$ & $51.21(17.24)$ \\
\hline Intensity (\%) & $72.96(21.44)$ & $58.33(20.03)$ & $45.70(21.28)$ & $50.94(24.37)$ \\
\hline Quality (\%) & $93.01(9.52)$ & $68.95(7.32)$ & $61.82(5.13)$ & $87.37(9.10)$ \\
\hline Liking of sample (\%) & $87.99(13.64)$ & $77.28(23.84)$ & $76.52(14.03)$ & $86.63(18.47)$ \\
\hline Hunger (\%) & $30.01(29.28)$ & $56.32(31.18)$ & $42.65(7.83)$ & $38.64(32.62)$ \\
\hline Liking in general (\%) & $96.33(4.69)$ & $81.18(16.87)$ & $78.49(7.11)$ & $91.47(14.00)$ \\
\hline Total & $N=48$ & & & \\
\hline
\end{tabular}

As a result, these variables were dropped from any further analyses

Using two separate $2 \times 2$ (colour $\times$ shape) ANOVAs, we tested if the groups differed in regard to state hunger levels and in their general regard for cheesecake. There were no significant main effects or interactions for either dependent variable, again suggesting relatively well matched groups.

\section{Analyses of attribute ratings}

Separate 2 (colour) $\times 2$ (shape) independent measures ANOVAs were conducted with each attribute (sweetness, intensity, quality, and liking) as the dependent variable. All analyses were tested at a significance level of .05 with a Bonferroni correction applied.

Regarding sweetness ratings, there was a significant main effect of colour with samples on white plates being rated as sweeter than those on black plates, $F(1,44)=$ 8.42, $P<.05, \eta_{\mathrm{p}}^{2}=.16$, but there was no main effect of plate shape. Most importantly however, was the presence of a significant colour $\times$ shape interaction, $F(1,44)=$ 6.70, $P<.05, \eta_{\mathrm{p}}^{2}=.13$. This interaction suggested that round white plates were rated significantly sweeter than square white plates $(\mathrm{t}(22)=3.04, P<.05)$ while there was no difference between the plate shapes for black plates (see Figure 1a).
For food intensity ratings, both the colour and shape main effects were significant; however, the significant interaction, $\mathrm{F}(1,44)=9.72, P<.05, \eta_{\mathrm{p}}^{2}=.18$, between the variables seemed to qualify the main effects. As with sweetness ratings, when compared to round black and square white plates, intensity ratings were significantly higher for round white plates, $\mathrm{t}(22)=4.12, P<.05$ and $\mathrm{t}(22)=4.01, P<.05$ respectively (see Figure $1 \mathrm{~b}$ ).

There were no significant main effects for either colour or shape on ratings of quality however, there was a significant interaction, $\mathrm{F}(1,44)=13.30, P<.05, \eta_{\mathrm{p}}^{2}=.23$. Post hoc tests revealed that three of the four pairings were significant (round white versus round black: $\mathrm{t}(22)=3.28$; round white versus square white: $t(22)=2.61$; round black versus square black: $t(22)=-2.55)$ and the fourth pairing (square white versus square black: $\mathrm{t}(22)=-1.84, P=.08$ ) approached significance (see Figure 1c).

Similar to quality ratings, there were no main effects of liking ratings but there was a significant interaction, $\mathrm{F}$ $(1,44)=7.29, P<.05, \eta_{\mathrm{p}}^{2}=.14$ (see Figure $1 \mathrm{~d}$ ). Post hoc tests revealed a significant colour effect for round plates $(t(22)=2.10)$ and a significant shape effect for black plates $(\mathrm{t}(22)=-2.43)$. The two other comparisons did not reach statistical significance (square white versus square black: $P=.09$; round white versus square white: $P=.12)$. 


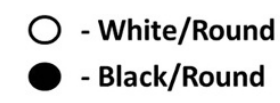

Sweetness

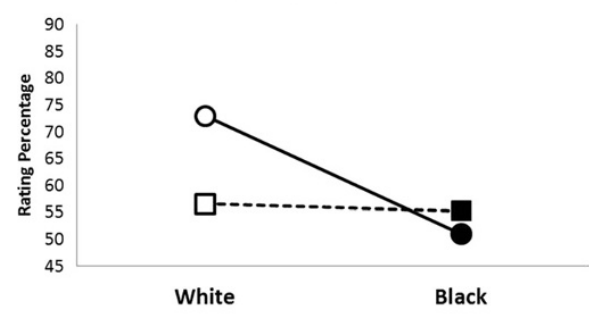

(a)

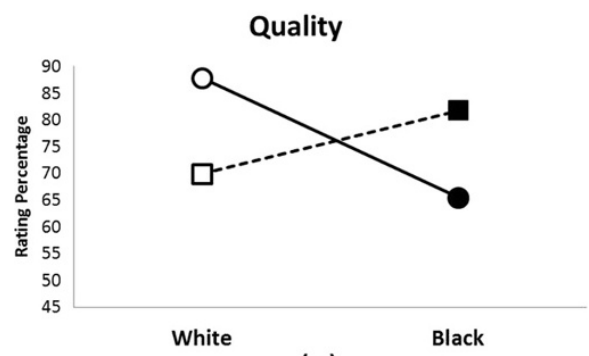

(c)

\section{$\square$ - White/Square \\ - Black/Square}

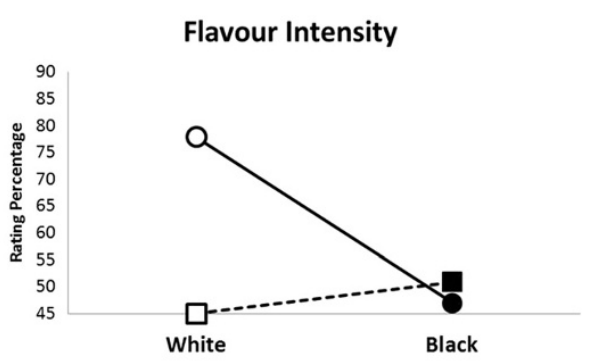

(b)

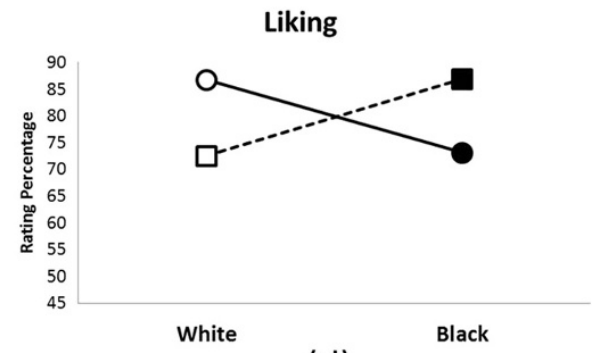

(d)

Figure 1 Significant plate colour by plate shape interactions on each of the attribute ratings. (a) Sweetness ratings: Food eaten on white round plates was rated significantly sweeter than that eaten on white square plates. (b) Intensity ratings: Food eaten from white round plates was rated significantly more intense than that eaten on white square plates. (c) Quality ratings: Food eaten on white round plates and black square plates was rated of significantly higher quality than that eaten on white square and black round plates. (d) Liking ratings: Food eaten on white round plates and black square plates was liked significantly more than that eaten on white square and black round plates. However, after considering participants' general regard for cheesecake, this interaction for liking ratings was negated.

The potential influences of hunger and general regard for cheesecake

Moskowitz et al. [28] showed that after a satiating intake of a glucose load, participants' ratings of pleasantness for subsequently presented sweet stimuli differed from participants who were sated from a standard breakfast or lunch. Although the current study did not gather very specific hunger-related information, to control for general hunger effects, we did collect a rating of state hunger. We also collected data pertaining to how much people generally liked cheesecake since it seemed likely that people who like a particular food will rate it differently than those who dislike the food or like it to a lesser extent. To examine these possibilities we conducted $2 \times 2$ analyses of covariance (ANCOVA) using ratings of hunger and general regard cheesecake as separate covariates for each of the four attributes (sweetness, liking, quality, and liking).

Neither self-reported levels of hunger nor levels of general cheesecake regard were significant covariates in analyses of sweetness or quality $(P>.05)$. However, both hunger levels and cheesecake regard levels were significant covariates when intensity ratings were analysed. With that said, and importantly, the interaction between plate colour and plate shape on intensity ratings remained significant when accounting for hunger levels, $\mathrm{F}(1,43)=8.65, P<.05$. When accounting for variance in intensity ratings due to general cheesecake regard, the interaction between plate shape and colour, $F(1,43)=$ 2.66, $P=.11$, was no longer significant although both main effects remained significant.

Interestingly, the strong interaction observed between plate colour and plate shape on liking ratings of the cheesecake sample was not influenced by the inclusion of hunger as a covariate but was completely nullified by the inclusion of participants' general regard for cheesecake as a covariate, $\mathrm{F}(1,43)=.45, P$ co .51 . This suggests that it is quite important to account for personal taste when analysing data of this sort.

\section{Discussion}

The current investigation examined the influence that plate shape and colour may have on the perceived sweetness, intensity, quality, and liking of a portion of cheesecake. It has been shown in the past that there is a white plate (over black) advantage but that plate shape did not significantly modulate attribute ratings [27]. Results of the current study, specifically the significant or near 
significant interactions across all attributes, suggest that both plate shape and plate colour are important but also that the relationship is anything but straightforward.

We have chosen to discuss these findings in terms of elemental versus compound judgments. By a compound judgment (for example, a judgment about quality or liking) we are referring to a higher level, gestalt judgment that is made by considering a number of individual elemental judgments (that is, judgments of sweetness, intensity, look, smell, etcetera) in order to come to what Delwiche [29] referred to as an emergent phenomenon. For example, when a quality judgment is made about a particular food, it seems likely that the final perception emerges from a combination of the look, smell, taste, context, and other elemental properties of the food. It is important to note that we are by no means suggesting that an elemental judgment is done on the basis of only one sensory modality; the background of this paper already suggested this is almost certainly not the case. We are rather saying that there are far fewer modalities involved with an elemental judgment than with a compound judgment. That is, people almost certainly judged sweetness by interpreting gustatory, visual, and olfactory input but it is less likely that quality or liking considerations factored into a sweetness rating. With that said, it is possible that there is an entirely nested reciprocal relationship between all these factors and future research could determine the validity of this possibility.

As can be seen in Figure 1(a,b), for elemental judgments (that is, sweetness and intensity) there was a clear white round plate enhancement suggesting that food served on this shape and colour plate leads to an increase in perceived sweetness and intensity. Although this needs to be extended to include different foods and plate attributes, this perceptual difference may have benefits to the food industry. We saw an approximate $20 \%$ increase in perceived sweetness and a 30\% rating increase in intensity when food was served on a white round plate. Perhaps an unsweetened or less sweet dessert when served on a white round plate would be better received than if it was served on a plate of a different colour and shape. Anecdotally, diabetics often complain that the only desserts they can eat do not taste sweet enough or taste bad due to the artificial sweeteners used. Potentially, the combination of a low sugar dessert on a white round plate would lead an improvement in the overall perception. Conversely, a common foodstuff that may be viewed as being too sweet could be served on a square white plate or a black plate to possibly dampen the perceived sweetness.

The results show a somewhat different story for compound judgments (that is, quality and liking). Figure 1 (c,d) shows that although there is still a white round plate advantage for ratings of quality and liking, there is also an advantage for square black plates. Since the participants' general liking of cheesecake seemed to explain the interaction effect observed for liking ratings, we limit our further discussion to the quality interaction. We contend that the white round plate advantage in quality judgments is being driven by elemental judgments that are perceptually increased by white round plates. For example, in this study we have shown that perceived sweetness and intensity are increased by the presentation of food on white round plates and it seems possible, if not likely, that other factors that were not measured in this experiment also show this white round plate preference. Quality being a compound judgment would be the sum of these elemental judgments and the end result would be a more positive quality judgment for food presented on white round plates. We further contend that this is a likely explanation for the square black plate advantage also obtained for judgments of quality. According to the Ecological Valence Theory (EVT), in regard to colour, our preference for a particular colour is determined by a sum total of our past experience with that colour, experience not necessarily specific to the object currently being perceived [30]. Humans tend to prefer colours that summon implicitly positive cognitive associations while disliking colours that spur the opposite. It seems reasonable that this would also extend to and combine with shape, although we are aware of no studies directly assessing this. Perhaps square black objects and white round objects have positive connotations when it comes to assessments of quality. Although this notion has yet to be extended to food, Schloss, Strauss, and Palmer [31] found that pure black (or white) T-shirts, dress shirts, ties/scarves, and squares were preferred over any shade of grey and that black ties/scarves were preferred. They suggested that for many objects people preferred subdued colours rather than flashy colours and that this preference was likely determined from experience with the object and/or colour. It is important to also consider that black is often seen and used in advertising to denote sophistication, luxuriousness, elegance, and quality. However, these potential associations with blackness do not aid in much in the explanation of black square plates. With that said, we suggest that the black square plate advantage in quality judgments may be due to the sum total of experience driven preferences. It would be interesting for future research to try and tease apart this plate effect using the EVT methodologies.

It is also possible that something as simple as the degree of familiarity is influencing participant attribute ratings. It seems likely that of the four plate types, white round plates are the most familiar and black square plates are the most novel. Sheau-Fen, Sun-May, and $\mathrm{Yu}$-Ghee [32] found that higher levels of familiarity were 
positively related with higher levels of perceived quality for a number of store brand consumer items. An opposing finding, yet actually complimentary for our purposes, is that consumer items that were judged to be unique or novel due to minor manipulations are judged as more desirable than the typical item [33]. Furthermore, Bornstein [34] concluded that although it is generally reproductively advantageous to prefer the typical to the novel it is at times advantageous (that is, during child development) to favour novel stimuli. Marrying these ideas together, the enhanced ratings observed for the food eaten from the white plates may be the result of familiarity while the obtained quality and liking enhancements for the black square plates may be due to novelty effects.

It is also known that the order in which participants complete questionnaire items can influence their answers to the questions. Malhotra [35] showed that ratings on simple questions, questions that are not challenging and take little effort, were susceptible to order effects. Since all participants in this study completed the attribute ratings in the same order (that is, sweetness followed by intensity followed by quality followed by liking), it is possible that each subsequent rating was influenced by the previous leaving sweetness ratings the only purely independent rating of the four. Without replicating the experiment we cannot know what effect this would have on the current data. However, because this was a between-subjects design and participants only viewed one plate type, there is no reason to predict that any potential order effect would be different for the black square group compared to any other group but future investigations may benefit from an order counterbalancing or randomization of rating items.

Although the square and round plates were of identical widths, the surface area of the round plates $\left(572 \mathrm{~cm}^{2}\right)$ was less than the square plates $\left(729 \mathrm{~cm}^{2}\right)$. Since the dimensions of our cake sample were consistent and we did find a white round plate enhancement across all ratings and a black square enhancement for quality and liking ratings, it is possible that both were surface area effects. Our data cannot rule out this possibility. Although a previous study by Rolls et al. [36] showed that food consumption was not different when served on plates of different sizes, this finding is not specific to taste judgments.

Finally, as previously stated, the Piqueras-Fiszman et al. [27] study reported no effect of plate shape on ratings of a strawberry mousse whereas the current study reports a new finding, a significant plate colour by plate shape interaction for all attributes. We have already mentioned a number of possible explanations for the pattern of results observed but it is important to address why a shape influence is observed in this study but not the previous [27]. Three reasons stand out for this. First, the authors of the previously mentioned study suggested that their square plates were rounded at the corners leading to a softening of any possible shape influences. We used square plates that had much sharper points at the corners. Perhaps the effect of shape would have been observed in the Piqueras-Fiszman et al. study if plates similar to our own were used [27]. Second, the manifestation of a shape effect in the current study could be because the food sample we used was different. The multisensory influences discussed may be food specific and where the previous authors used strawberry mousse, we used cheesecake. This food stuff difference alone may be enough to explain the shape influence observed here but it could also be a function of the shape of the food, the colour of the food, or some interaction of these variables. Lyman [37] suggested that taste perception may be influenced by figure-ground (that is, food-plate) contrasts. That is, perceptions of taste may vary between foods of different colours, especially when served on different colour plates. Parallel possibilities may also exist for shape variables. As such, the differences in findings between Piqueras-Fiszman et al. [27] and the current study might be explained by these contrast differences. The different results may be due to their mousse samples being a different colour (reddish) and presented in a different shape (half sphere or pyramidal) than our cheesecake sample (yellowish and cylindrical). Future research might systematically vary the food (or plate) colour/shape to investigate the influence of simultaneous contrast on taste perception. Finally, a third possibility is that the interactions we observed in our study may have been observed in the Piqueras-Fiszman et al. study had they been evaluated [27].

\section{Conclusions}

The results of this experiment suggest that the influence of plate colour and shape on taste perception is, not surprisingly, more complex than expected. There appears to be a substantial white round plate advantage although, black square plates have their place also. It seems that basic judgments (that is, sweetness or intensity) are enhanced by white round plates while more complex judgments (that is, quality or liking) are enhanced by both white round and black square plates. We suggest that this may be due to specific learned associations or some sort of familiarity/novelty effect.

Regardless of what is driving this effect, the knowledge that plate shape and plate colour do interact to influence taste perceptions is important to the culinary industry. Chefs certainly want their food to taste a certain way. Knowing that food presented on a white round plate will be perceived as sweeter, for example, would allow them to modify the sweetness levels of their product such that the desired level of perceived sweetness is achieved. 


\section{Methods}

\section{Participants}

A total of 48 individuals ( 27 males and 21 females), ranging in age from 16 to 54 years old $(M=22.23, S D=$ $6.68)$, volunteered to participate in the study. Genders did not differ in age, $\mathrm{t}(46)=-1.70, P>.05$. All participants voluntarily stopped by two tables set up in the university cafeteria and initially completed a standard informed consent process which additionally involved reporting any food- or ingredient-related allergies. An ingredient list was made available to participants but, for safety reasons, any participant who reported a foodrelated allergy was thanked for their interest but not permitted to take part in the study. This study received ethics approval from the Grenfell Campus, Memorial University Research Ethics Board.

\section{Materials}

President's Choice $\left(\mathrm{PC}^{\mathrm{rm}}\right)$ pre-packaged Original New York style cheesecake was used as the food stimulus. It was presented in a cylindrical fashion, with each portion cut to the same size $(6.5 \mathrm{~cm}$ in diameter $)$ via a biscuit cutter. Black and white porcelain plates of circular and square shapes were used along with tablecloths, napkins, and plastic spoons. Although the overall surface area was greater for the square plates, keeping the diameter/ width of the round and square plates equal $(27 \mathrm{~cm})$ was thought to be more important (see Figure 2). With that said, the proportion of surface area covered by food has been shown to play a role in perception and should potentially be controlled for in future studies [38].

A questionnaire, adapted from Piqueras-Fiszman et al. [27], was used to gather information on participants' perceptions of the cheesecake sampled. Responses to questions regarding sweetness, intensity, quality, and liking were made on unstructured $10 \mathrm{~cm}$ scales, each anchored with 'Not at all sweet,' 'Not at all intense,' 'Very low quality', and 'Extremely dislike' on the left ends, and 'Very sweet', 'Very intense', 'Very high quality', and 'Extremely like' on the right ends. Participants were required to place an ' $\mathrm{X}$ ' on each scale wherever they thought best represented their experience of the food sampled. Two further questions assessed participants' hunger at the time of the study and their general regard for cheesecake. Responses to these were also made on unstructured scales but were anchored with 'Extremely hungry' and 'Extremely dislike' on the left, and 'Extremely full' and 'Extremely like' on the right. Participant age and gender were also recorded.

\section{Procedure}

One round table was used to present the questionnaires and copies of the informed consent form while the second table, which was covered in a transparent plastic

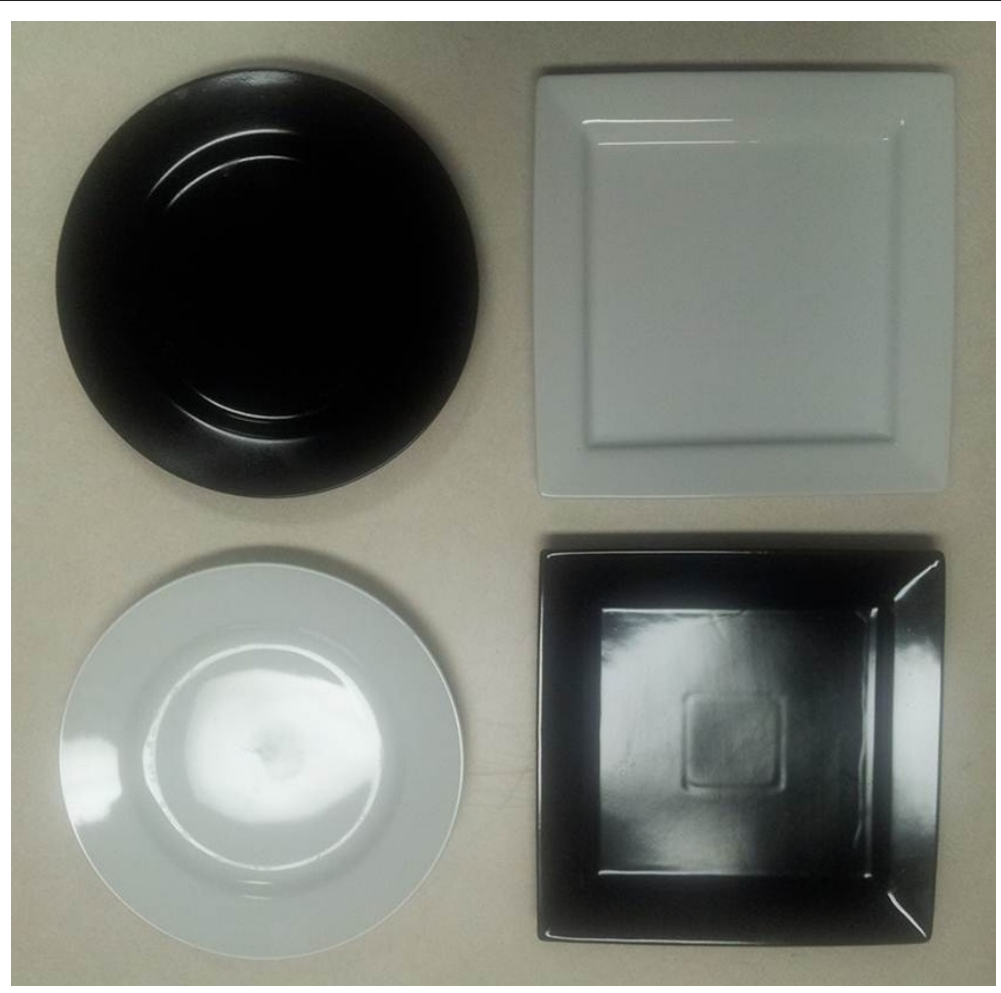

Figure 2 The four plate types. 


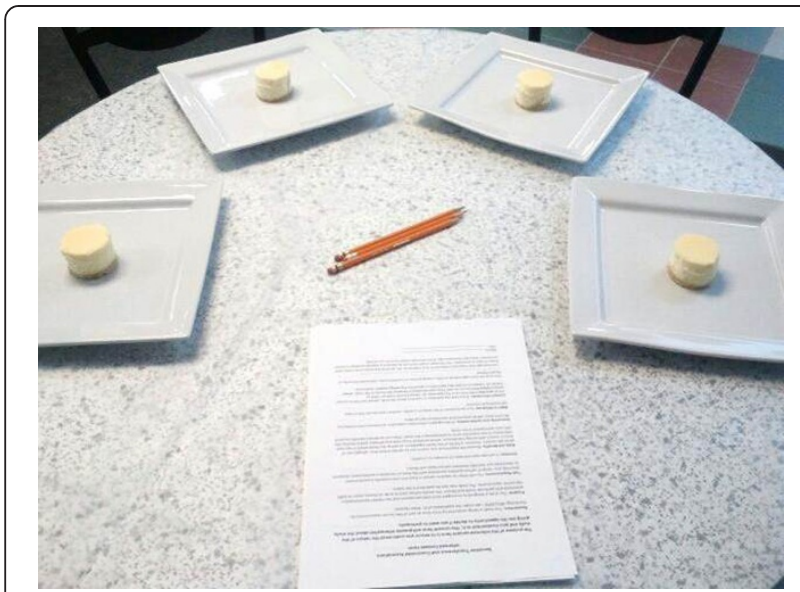

Figure 3 Table set-up for a trial of plates from one experimental condition (white square). No participant ever saw more than one type of plate.

tablecloth, presented the samples to be tasted. Data were collected in blocks with each block consisting of four plates corresponding to one of the four conditions. Each block was repeated three times, in a pseudo-random order, for a total of 12 trials per plate condition. The four plates were spaced equally apart on the half of the table opposite of the researcher and the circular portion of cheesecake was situated in the centre of each plate (see Figure 3).

Volunteer participants were asked whether they possessed any food-related allergies and if they did not, they were invited to begin the experiment by completing an informed consent process. The true nature of the study was withheld from participants until the debriefing session and instead participants were told they would take part in a taste test. At no point during their participation were subjects aware that this was a taste perception study comparing plate colour and shape. Participants were then seated at the table in front of one of the four plates and were instructed to not touch the plate and to refrain from conversing with other participants. As the cheesecake had a layer of graham crumbs as its lowest layer, with the rest of the cake composition being uniform, the participants were instructed to taste one spoonful from the top of the sample using the spoon provided. Participants then immediately completed the questionnaire and were then permitted to finish their cheesecake. Once the questionnaire was completed, participants were given a second copy of the informed consent form to keep for their own records, and a debriefing form explaining the true purpose of the study was provided. Any questions they had were answered and they were told how/when they could obtain the group results of the experiment. To avoid biasing any other potential participants, all participants were asked to not discuss, for a period of three days, the true nature of the study with incoming participants or anyone else who may participate.

\section{Endnote}

${ }^{\mathrm{a}} \mathrm{A} 2 \times 2$ analysis of variance (ANOVA), with plate shape and plate colour as factors and age as the dependent variable, revealed no significant interaction or main effects. Further, age was not significantly correlated with any dependent variable. Both analyses suggested that the groups were well matched for age, and that age, at least within the age range measured here, seemed to not be predictive of judgments of sweetness, intensity, quality, or liking. We also examined if the groups differed in composition with regard to gender. Two chisquare tests, one for each plate colour, examined any relationship between plate shape and gender. There was no significant relationship observed for white plates suggesting similar gender compositions across plate shape conditions. However, for black plates a significant relationship was found between plate shape and gender, $\chi^{2}=4.20$, $P<.05$, with significantly more females in the black square condition compared to the black circle condition. To further assess if gender was influencing the attribute ratings we again conducted ANCOVAs, using gender as a covariate, for each of the four attributes. Gender was not a significant covariate for any of the analyses $(P>.05)$, suggesting that the gender difference in group compositions did not confound the obtained results.

\section{Competing interests}

The authors declare that they have no conflicts of interest, financially or otherwise.

\section{Authors' contributions}

PS conceived of the study, participated equally with EG in the study design and data analysis, and drafted/revised the manuscript. EG completed the data collection and aided in the initial stages of manuscript preparation. All authors have read and approved the final manuscript.

\section{Acknowledgements}

The authors appreciate the support of Grenfell Campus, Memorial University of Newfoundland for the funding used to purchase study materials and for allotting space in the university cafeteria. The authors also wish to thank all participants who volunteered to complete the study and the anonymous reviewers who aided in manuscript preparation.

Received: 14 June 2013 Accepted: 4 October 2013

Published: 25 October 2013

\section{References}

1. Frank RA, Byram J: Taste-smell interactions are tastant and odorant dependent. Chem Senses 1988, 13:445-455.

2. Cliff M, Noble AC: Time-intensity evaluation of sweetness and fruitiness and their interaction in a model solution. J Food Sci 1990, 55:450-454.

3. Clark CC, Lawless HT: Limiting response alternatives in time-intensity scaling: an examination of the halo dumping effect. Chem Senses 1994, 19:583-594.

4. Stevenson RJ, Prescott J, Boakes RA: Confusing tastes and smells: How odours can influence the perception of sweet and sour tastes. Chem Senses 1999, 24:627-635. 
5. Djordjevic J, Zatorre RJ, Jones-Gotman M: Odor-induced changes in taste perception. Exp Brain Res 2004, 159:405-408

6. Pangborn RM, Trabue IM, Szczesniak AS: Effect of hydrocolloids on oral viscosity and basic taste intensities. J Texture Stud 1973, 4:224-241.

7. Okajima K, Spence C: Effects of visual food texture on taste perception. ; 2011 http://i-perception.perceptionweb.com/journal///article/ic966.

8. Saint-Eve A, Deleris I, Panouille M, Dakowski F, Cordelle S, Schlich P, Souchon I: How texture influences aroma and taste perception over time in candies. Chem Percept 2011, 4:32-41.

9. Cook DJ, Hollowood TA, Linforth RST, Taylor AJ: Perception of taste intensity in solutions of random-coil polysaccharides above and below c*. Food Qual Prefer 2002, 13:473-480.

10. Walker S, Prescott J: The influence of solution viscosity and different viscosifying agents on apple juice flavor. J Sensory Stud 2000, 15:285-307.

11. Salles C, Chadnon M-C, Feron G, Guichard E, Laboure H, Morzel M, Semon E, Tarrega A, Yven C: In-mouth mechanisms leading to flavor release and perception. Critic Rev Food Sci Nutr 2011, 51:67-90.

12. Cytowic RE: The Man Who Tasted Shapes: A Bizarre Medical Mystery Offers Revolutionary Insights Into Reasoning, Emotion, and Consciousness. New York: Putnam; 2003.

13. Lehrer A: Wine \& Conversation. 2nd edition. Oxford: Oxford University Press; 2009.

14. Ngo MK, Misra R, Spence C: Assessing the shapes and speech sounds that people associate with chocolate samples varying in cocoa content. Food Qual Prefer 2011, 22:567-572.

15. Ngo MK, Spence C: Assessing the shapes and speech sounds that consumers associate with different kinds of chocolate. J Sensory Stud 2011, 26:421-428.

16. Moir HC: Some observations on the appreciation of flavor in food stuffs. Chem Indust 1936, 55:145-148.

17. Heckler SE, Childers TL: The role of expectancy and relevancy in memory for verbal and visual information: What is incongruency? J Consume Res 1992, 18:475-492.

18. Stillman JA: Color influences flavor identification in fruit-flavored beverages. J Food Sci 1993, 58:810-812.

19. Dubose CN, Cardello AV, Maller O: Effects of colorants and flavorants on identification of perceived flavor intensity, and hedonic quality of fruitflavored beverages and cakes. J Food Sci 1980, 45:1393-1399.

20. Garber LL, Hyatt EM, Starr RG: The effects of food color on perceived flavor. J Market Theor Prac 2000, 8:59-72.

21. Spence $C$, Harrar V, Piqueras-Fiszman B: Assessing the impact of the tableware and other contextual variables on multisensory flavour perception. Flavour 2012, 1:12

22. Crisinel A, Cosser S, King S, Jones R, Petrie J, Spence C: A bittersweet symphony: systematically modulating the taste of food by changing the sonic properties of the soundtrack playing in the background. Food Qual Prefer 2012, 24:201-204.

23. Piqueras-Fiszman B, Laughlin Z, Miodownik M, Spence C: Tasting spoons: assessing the impact of the material of the spoon on the taste of the food. Food Qual Prefer 2012, 24:24-29.

24. Spence C, Ngo M: Assessing the shape symbolism of the taste, flavour, and texture of foods and beverages. Flavour 2012, 1:12.

25. Oberfeld $D$, Hecht $H$, Allendorf $U$, Wickelmaier F: Ambient lighting modifies the flavour of wine. J Sensory Stud 2009, 24:797-832

26. Irmak C, Vallen B, Robinson SR: The impact of product name on dieters' and nondieters' food evaluations and consumption. J Consume Res 2011 38:390-405

27. Piqueras-Fiszman B, Alcaide J, Roura E, Spence C: Is it the plate or is it the food? Assessing the influence of the color (black or white) and shape of the plate on the perception of the food placed on it. Food Qual Prefer 2012, 24:205-208.

28. Moskowitz HR, Kumraiah V, Sharma KN, Jacobs HL, Sharma SD: Effect of hunger, satiety and glucose load upon taste intensity and taste hedonics. Physiol Behav 1976, 16:471-475.

29. Delwiche JF: You eat with your eyes first. Physiol Behav 2012, 107:502-504.

30. Palmer SE, Schloss KB: An ecological valence theory of human color preference. Proc Nat Acad Sci 2010, 107:8877-8882.

31. Schloss KB, Strauss ED, Palmer SE: Object color preferences. Color Res App/ 2012, 38:393-411.

32. Sheau-Fen Y, Sun-May L, Yu-Ghee W: Store brand proneness: effects of perceived risks, quality and familiarity. Austr Market J 2012, 20:48-58
33. Carpenter GS, Glazer R, Nakamoto K: Meaningful brands from meaningless differentiation: the dependence on irrelevant attributes. J Market Res 1994, 31:339-350.

34. Bornstein R: Exposure and affect: overview and meta-analysis of research, 1968-1987. Psycholog Bull 1989, 106:265-289.

35. Malhotra N: Order effects in complex and simple tasks. Pub Opin Quart 2009, 73:180-198.

36. Rolls BJ, Roe LS, Halverson $\mathrm{KH}$, Meengs JS: Using a smaller plate did not reduce energy intake at meals. Appetite 2007, 49:652-660.

37. Lyman B: A Psychology of Food: More Than a Matter of Taste. New York: Avi van Nostrand Reinhold; 1989.

38. Zampollo F, Wansink B, Kniffin KM, Shimizu M, Omori A: Looks good enough to eat: How food plating preferences differ across cultures and continents. Cross-Cult Res 2012, 46:31-49.

doi:10.1186/2044-7248-2-27

Cite this article as: Stewart and Goss: Plate shape and colour interact to influence taste and quality judgments. Flavour 2013 2:27.

\section{Submit your next manuscript to BioMed Central and take full advantage of:}

- Convenient online submission

- Thorough peer review

- No space constraints or color figure charges

- Immediate publication on acceptance

- Inclusion in PubMed, CAS, Scopus and Google Scholar

- Research which is freely available for redistribution 